\title{
ESTUDO DE VIABILIDADE PARA IMPLEMENTAÇÃO DE CORREDORES ECOLÓGICOS NA ILHA DO MARANNHÃO
}

\author{
Yata Anderson Gonzaga Masullo ${ }^{1}$ \\ Claudio Eduardo de Castro ${ }^{2}$ \\ Roberta Capim Rocha ${ }^{3}$
}

\begin{abstract}
Resumo: A presente pesquisa desenvolve-se com a finalidade de analisar a viabilidade de implantação de corredores ecológicos na Ilha do Maranhão, a partir de técnicas ligadas aos Sistemas de Informações Geográficas (SIGs). O estudo de viabilidade consistiu na sobreposição de mapas temáticos, elaborados a partir da delimitação do uso e ocupação da terra (variáveis ambientais), consideradas como unidades de paisagem. Para tanto utilizou-se do método Multicritério Processo de Análise Hierárquica alicerçado por técnicas ligadas ao Sistema de Informação Geográfico - SIGs, com o objetivo de correlacionar os indicadores socioambientais que influenciam e caracterizam a dinâmica da paisagem e a qualidade de vida das UCs. A partir destes procedimentos foi possível mensurar a viabilidade na implantação de três corredores ecológicos interligando as Unidades de Conservação - UCs da Ilha do Maranhão. Assim, a presente pesquisa reflete a necessidade de se implementar intervenções específicas, que possibilitem ações as quais possam englobar todas as áreas protegidas.
\end{abstract}

Palavras-chave: Corredores Ecológicos; Análise Multicritério; Grande São Luís.

\section{FEASIBILITY STUDY FOR THE IMPLEMENTATION OF ECOLOGICAL CORRIDORS IN MARANHÃO ISLAND}

\begin{abstract}
The present research is developed with the purpose of analyzing the feasibility of implementing ecological corridors in the Island of Maranhão, using techniques related to Geographic Information Systems (GIS). The feasibility study consisted of overlapping thematic maps, elaborated from the delimitation of land use and occupation (environmental variables), which are considered as landscape units. For this purpose, the multi-criteria method was used. Hierarchical Analysis Process based on techniques linked to the Geographic Information System - GIS. In order to correlate socio-environmental indicators that influence and characterize landscape dynamics and the quality of life of protect areas. Based on these procedures, it was possible to measure the viability of the implementation of three ecological corridors connecting the Conservation Units - UC's of the Island of Maranhão. Thus, the present research reflects the need to implement specific interventions that allow actions that can encompass all areas protected.
\end{abstract}

Keywords: Ecological Corridors; Multicriteria Analysis; Great São Luís.

\footnotetext{
1 Assessor Especial da Secretaria Adjunta de Assuntos Metropolitanos - SAAM, Pesquisador do Instituto Maranhense de Estudos Socioeconômicos e Cartográficos - IMESC, Consultor da Empresa Ambiental Gestão de Projetos e auxiliar de pesquisa do Laboratório de Geografia, Ambiente e Saúde - LAGAS/UnB. Email: yanderson3@hotmail.com

${ }_{2}^{2}$ Professor titular da Universidade Estadual do Maranhão. Email: clanaros@ yahoo.com.br

${ }^{3}$ Graduanda em Ciências Ambientais pela Universidade de Brasília - UNB. Email: robertarocha123@outlook.com
} 


\section{ESTUDIO DE VIABILIDAD PARA LA IMPLEMENTACIÓN DE CORREDORES ECOLÓGICOS EN LA ISLA DE MARANHÃO}

Resumen: La presente investigación se desarrolla con la finalidad de analizar la viabilidad de implantación de corredores ecológicos en la Isla de Maranhão, a partir de técnicas ligadas a los Sistemas de Informaciones Geográficas (SIGs). El estudio de viabilidad consistió en la superposición de mapas temáticos, elaborados a partir de la delimitación del uso y ocupación de la tierra (variables ambientales), que son considerados como unidades de paisaje. Para ello se utilizó el método multicriterio proceso de análisis jerárquico basado en técnicas ligadas al Sistema de Información Geográfico - SIG's. Con el objetivo de correlacionar los indicadores socioambientales que influencian y caracterizan la dinámica del paisaje y la calidad de vida de las UC's. A partir de estos procedimientos fue posible medir la viabilidad en la implantación de tres corredores ecológicos interconectando las Unidades de Conservación UC's de la Isla de Maranhão, Así, la presente investigación refleja la necesidad de implementar intervenciones específicas, que posibiliten acciones que puedan englobar todas las áreas protegidas.

Palabras claves: Corredores Ecológicos; Análisis Multicriterio; São Luís.

\section{INTRODUÇÃO}

A criação de espaços visando à proteção dos recursos naturais de forma integrada é cada vez mais necessária diante do atual cenário em que vivemos, caracterizados principalmente pela expansão urbana, aliados a um modelo de crescimento econômico, no qual a exploração dos recursos ambientais, propicia cada vez mais impactos ambientais (PEDLOWSKI et al., 1999). Atualmente, 12\% da superfície terrestre são consideradas como áreas protegidas segundo os critérios da União Internacional para a Conservação da Natureza (IUCN), (LEVERINGTON et. al.2010). O Brasil, se considerararmos apenas as Unidades de Conservação ( UC's), possui cerca de $18 \%$ do território continental brasileiro ou seja, 1,5 milhões km² (MMA, 2017).

As tipologias de proteção no Brasil são definidas pelo Sistema Nacional de Unidades de Conservação (SNUC), Lei no 9.985/2000 (BRASIL, 2000) que em seu Art. 2º, inciso I, caracteriza-as como espaços territoriais legalmente instituídos pelo poder público, objetivando a conservação de seus recursos ambientais, sob regime especial de administração e denominando-as de Unidades de Conservação (UC). Corroborando com essa afirmação Bursztyn; Bursztyn (2012) considera que as UC's são áreas com características naturais e/ou culturais relevantes, definidas pelos governos federal, estaduais e municipais, visando à preservação de ecossistemas e a utilização de forma adequada e sustentável do ambiente.

Nesse contexto, nos municípios da Ilha do Maranhão (São Luís, São José de Ribamar, Paço do Lumiar e Raposa), localizam-se UC's inseridas com diferentes características e singularidades. Entre estas UC's estão as de proteção integral (Parque 
Estadual do Sítio do Rangedor, Parque Estadual do Bacanga, além do Parque das Dunas, que está em processo de criação), no qual os recursos protegidos não podem ser utilizados, senão, indiretamente, e de uso sustentável (APA's do Itapiracó, Maracanã, Upaon-Açu-MiritibaAlto Preguiças; Parque Ecológico Laguna da Jansen e Sítio Santa Eulália), nos quais os recursos podem ser utilizados de forma sustentável.

Esta região apresentou, nas últimas décadas, um intenso processo de urbanização, o que ampliou a importância desses espaços como uma significativa ferramenta, no que diz respeito à proteção de seus recursos naturais. Segundo Bueno; Ribeiro (2007), além da proteção da fauna, flora e demais recursos naturais, estes espaços desempenham um papel educacional e interpretativo muito importante, para conservação, preservação e valoração do meio ambiente.

No entanto, Costa et al. (2008), advertem que uma vez localizadas em áreas urbanizadas, as UC's estão expostas a impactos cada vez mais acentuados, oriundos das atividades humanas, como a deposição de resíduos sólidos e supressão vegetal.

Tal realidade reflete a ineficiência do planejamento e gestão destes espaços, que, em sua maioria, apresentam físcalização deficiente, ausência de regulamentação fundiária, inexistência ou desatualização de planos de manejo, como também falta de recursos financeiros e humanos.

No intuito de conservar e mitigar a precariedade do cenário da gestão e planejamento nestes espaços fez-se necessário pensar em implementação de práticas e metodologias, como, por exemplo, corredores ecológicos (VALENTI et al., 2012; ARANHA; ALMIRANTE, 2007). Definidos pelo SNUC, Art. $2^{\circ}$ inciso XIX como porções de ecossistemas naturais ou seminaturais, objetivando a ligação de unidades de conservação e, consequentemente possibilitando um maior fluxo de genes e movimento da biota, assim como a recolonização de áreas degradadas (BRASIL, 2000).

Esta pesquisa objetiva desenvolver um estudo de viabilidade de corredores ecológicos na Ilha do Maranhão, entre os municípios de São Luís, São José de Ribamar, Paço do Lumiar e Raposa, a partir de técnicas ligadas aos Sistemas de Informações Geográficas (SIGs). O trabalho visa fornecer bases para otimização à implementação de políticas públicas intrinsecamente ligadas à conservação da geodiversidade em diferentes escalas.

Com intuito de alcançar os objetivos, utilizou-se da abordagem sistêmica, relacionando condicionantes sociais, econômicos e ambientais. Para estruturação dos mesmos, os procedimentos metodológicos foram baseados e modificados a partir de Gascon; 
Tabarelli (2005); Louzada et al. (2010); Araújo et al. (2014), para análise das múltiplas variáveis socioambientais.

Desta forma, a pesquisa estruturou-se a partir da análise das UC's da Ilha do Maranhão com enfoques local e regional, sob uma abordagem sistêmica. Posteriormente fezse uma revisão bibliográfica quanto ao uso dos Corredores Ecológicos como estratégia para conservação, abordando sua importância como ferramenta de interligação de UC's, mas também como meio de preservação e conservação da geodiversidade.

Finalmente, visando a proposição e viabilidade na aplicação de Corredores Ecológicos, contribuiu-se de forma específica para o planejamento de ações voltadas para a conservação e proteção das UC's da Ilha do Maranhão. Essa necessidade tornou-se um desafio ainda maior quando se observou a formação das nossas grandes cidades, hoje, reconhecidas como metrópoles. Observou-se que seja qual for sua configuração territorial, estas tendem à fragmentação e dominação por interesses políticos locais, que não abrem mão do poder em favor do coletivo (MASULLO; LOPES, 2016).

\section{ÁREA DE ESTUDO}

Nesse ambiente de grande aglomeração urbana da Região Metropolitana da Grande São Luís - RMGSL, estão situadas Unidades de Conservação - UC's da Área de Proteção Ambiental do Maracanã, Estação Ecológica do Rangedor, Área de Proteção Ambiental do Itapiracó, Área de Proteção Ambiental Upaon - Açu - Miritiba - Alto do Rio Preguiças, Sítio Santa Eulália, Parque Ecológico da Lagoa da Jansen, Parque das Dunas, Parque Estadual do Sítio Rangedor e o Parque Estadual do Bacanga (Figura 01). 


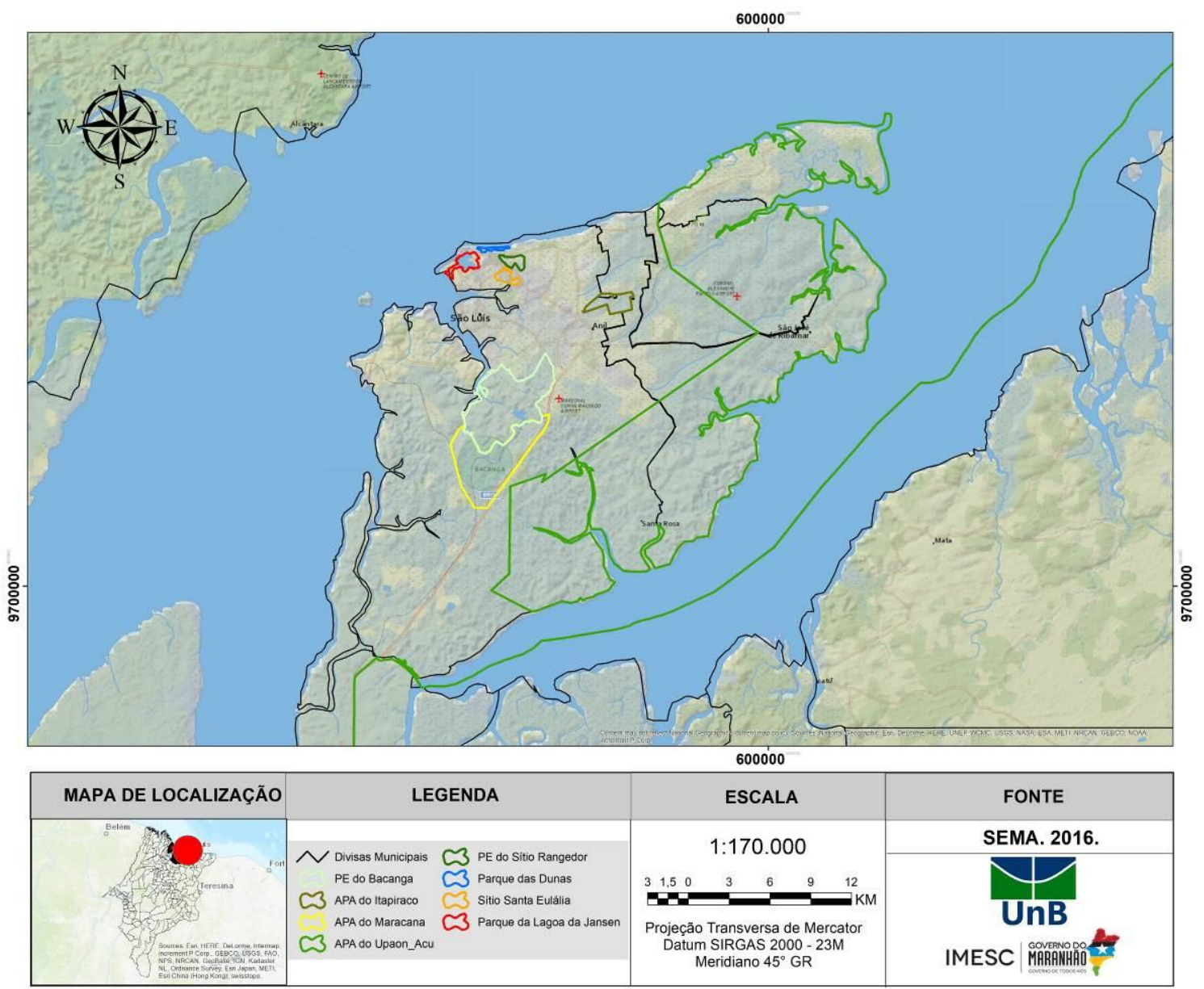

Figura 01: Mapa de Localização RMGSL e UC's Fonte: Elaborado pelo autor (2017).

Dentre as UC's, localizadas na Ilha do Maranhão, está o Parque Estadual do Bacanga, criado em 1980 e considerado a primeira Unidade de Conservação do Estado. Localizado em São Luís, o PE do Bacanga tem o objetivo de proteger a margem direita do Rio Bacanga e a Bacia do Maracanã, região que possui rios que abastecem cerca de $30 \%$ da Ilha do Maranhão.

Também em 1991, foram criadas a APA do Maracanã, apresentando solo rico em matéria orgânica e fauna característica de rios que abastecem a capital. Já em 1992, foi criada a APA Upaon - Açu - Miritiba - Alto do Rio Preguiças abrangendo uma extensa área. Surgiu com o objetivo de servir de berçário para diversas espécies.

Em 1997, criou-se a APA do Itapiracó, resultado de parceria entre a ALUMAR e várias entidades para proteção das nascentes do Rio Paciência (MASULLO; MAGALHÃES, 2015). Já o Parque Estadual do Sítio do Rangedor tem por objetivo a preservação de remanescentes florestais em São Luís, funcionando como importante área verde e corredor ecológico para espécies migratórias, além de possibilitar a realização de pesquisas científicas. 
Foi criada em 2005 como Estação Ecológica, no entanto, através do projeto de Lei $\mathrm{N}^{\circ}$ $321 / 2015$, terminou por ser recategorizada.

O Parque Ecológico da Lagoa da Jansen foi criado pelo Decreto Estadual n 4.878 , de 23 de junho de 1988, entre os bairros do São Francisco, Ponta D’areia, Renascença I e II e Ponta do Farol, na região central de São Luís (ROCHA; MASULLO, 2016). Em relação ao Sítio Santa Eulália, instituído pelo Macrozoneamento Ambiental do município de São Luís (Lei No 4.669 de 11 de outubro de 2006) e de propriedade do Fundo de Pensão dos Servidores do Estado, apresenta significativo patrimônio natural com vegetação densa de várzea e mangue, principalmente às margens do Igarapé do Vinhais, que deságua no Rio Anil (BONTEMPO, 2008).

\section{MATERIAIS E MÉTODOS}

Para a construção de cenários dos corredores ecológicos utilizou-se técnicas em SIGs sob uma abordagem sistêmica multidisciplinar, baseada em Morin et al (2003). Dentre os métodos multicritérios optou-se pelo reconhecido Processo Hierárquico Analítico (AHPAnalytical Hierarchy Process, em inglês) que consiste em modelagem de dados que permitam a ponderação de diversos fatores envolvidos em processos de diagnósticos e tomadas de decisão, auxiliando a integração objetiva de indicadores (OLIVEIRA, 2008).

O método desenvolvido por Saaty, em 1977, é uma técnica que possui a finalidade de atenuar a subjetividade das interpretações através do estabelecimento de uma hierarquia de soluções com quantificação dos atributos e suas correlações (DIAS, 2014). Contribuindo com a construção conceitual, Saito (2015) e Argyriou et al. (2016) visualizaram o método AHP como uma estrutura hierárquica de decisão, composta por níveis de importância com uma visão holística das relações inerentes ao processo, onde existe a categorização e ponderação de matrizes de comparação para cada nível.

Conforme Silva Júnior (2015), a obtenção do modelo hierárquico depende da construção de matrizes quadradas recíprocas positivas, cuja ordem será igual ao número de alternativas. Posteriormente, para cada critério ou subcritério fez-se o mesmo progressivamente, para definir o grau de importância de cada uma das variáveis, contribuindo com a funcionalidade e coerência nos níveis de correlação (Quadro 01). 


\section{MASULLO, CASTRO, CAPIM}

\begin{tabular}{|cc|}
\hline $1 / 9$ & Extremamente menos importante que \\
\hline $1 / 7$ & Muito fortemente importante que \\
\hline $1 / 5$ & Fortemente menos importante que \\
$1 / 3$ & Moderadamente menos importante que \\
\hline 1 & Igualmente importante a \\
\hline 3 & Moderadamente mais importante que \\
\hline 5 & Fortemente mais importante que \\
\hline & Muito fortemente mais importante que \\
& Extremamente mais importante que \\
& $\begin{array}{c}\text { Quadro 01: Escala de Comparadores. } \\
\text { Fonte: Louzada } \text { et al. (2010). }\end{array}$
\end{tabular}

Esse procedimento baseia-se em três princípios: $1^{\circ}$-decomposição, $2^{\circ}$-julgamentos comparativos e $3^{\circ}$-síntese de prioridades, cuja estrutura hierárquica delimita-se em Nível I (Objetivo a ser alcançado), Nível II (critérios) e Nível III (alternativas). Desta forma, definese o peso de cada uma das variáveis e/ou indicadores com sua soma igual a 1, como uma condição necessária para a combinação linear ponderada dos critérios (CONDE, 2013; DIAS 2014).

De acordo com Raffo (2012); Sahoo et al. (2016), essa estrutura possibilita, a partir de variáveis selecionadas, que se estabeleçam cenários para tomada de decisão. Em suma, o método AHP pondera, quantitativamente, variáveis mediante correlações qualitativas, organizando e estabelecendo um modelo racional de combinação de dados Gauer (2015).

A coleta de dados UC e RMGSL: A pesquisa documental se desenvolveu através da consulta nas Secretarias de Estado das Cidades e Desenvolvimento Urbano - SECID, de Meio Ambiente Estadual e Ministério do Meio Ambiente. Além dos dados institucionais estruturou-se a análise bibliográfica a partir de estudos nacionais e internacionais, por meio do portal de periódicos da CAPES (Coordenação de Aperfeiçoamento de Pessoal de Nível Superior), SCIELO e Google Acadêmico. Quanto a coleta de dados in loco realizou-se com a finalidade de validar as informações levantadas na pesquisa cartográfica, bem como dirimir dúvidas da fotointerpretação e fazer registros fotográficos.

B: Corredores Ecológicos: O desenvolvimento do estudo, baseia-se nas metodologias de Tabarelli; Gascon (2005); Louzada et al. (2010); Marques, et al. (2011); Araújo et al. (2014). Nestas, utiliza-se o SIG para analisar variáveis ambientais múltiplas, como forma de propor um modelo para desenho de interligação das UC's da Ilha do Maranhão por meio de corredores ecológicos (Figura 02). 


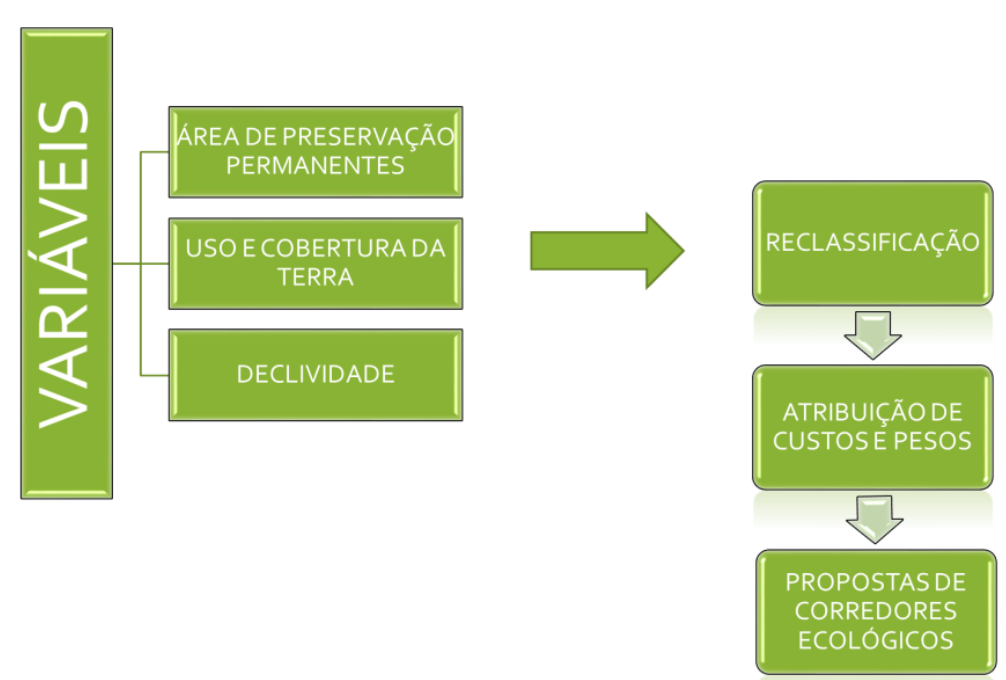

Figura 02: Fluxograma dos procedimentos técnicos.

Fonte: Elaborado pelo autor (2017).

Essa análise consiste na sobreposição de mapas temáticos elaborados a partir da delimitação do uso e ocupação da terra (variáveis ambientais), considerados como unidades de paisagem. Para cada variável ambiental atribuiu-se um peso de acordo com Gascon; Tabarelli (2005); Louzada et al, 2010). Posteriormente, estes foram utilizados como base de cálculo, gerando variáveis ambientais a serem utilizadas na confecção dos mapas temáticos: Área de Preservação Permanente (APP); uso da terra; declividade e; presença das UC's.

Estes dados foram extraídos a partir do processamento digital das imagens aéreas com resolução espacial de 0,5 m do ano de 2011 cedidas pela Prefeitura de São Luís servindo como base à fotointerpretação, com o uso do software ArcGIS 10.2. Para a declividade foram utilizadas imagens radar (SRTM) de 30 metros de resolução espacial obtidas no site da Earth Explorer, geradas curvas por interpolação, quando necessário.

Para o processamento e classificação supervisionada empregou-se um sistema de amostragem por regiões, utilizando a informação espectral de cada "pixel", atrelado à informação espacial que envolve a relação com seus vizinhos. Neste processo foi utilizado o classificador de Máxima Verossimilhança (MaxVer) do ArcGIS 10.2, que considera a ponderação das distâncias entre as médias dos valores dos pixels das classes, utilizando parâmetros estatísticos (NASCIMENTO et. al, 2016).

As variáveis foram convertidas para o formato matricial e reclassificadas aos respectivos componentes da legenda, recebendo valores referentes ao objetivo de análise, e estes, segundo cada classe temática da variável (LOUZADA et al, 2010). As classes que inviabilizam os corredores ecológicos receberam valores mais elevados, em uma escala de 
variação de 1 a 100. Para a variável Uso e Cobertura da Terra, Declividade, Área de Preservação Permanente, foram inferidos os custos dos Quadros 02 a 04:

\begin{tabular}{|c|c|}
\hline USO E COBERTURA DA TERRA & CUSTOS \\
\hline Floresta & 1 \\
\hline Vegetação Secundária & 10 \\
\hline Área Urbana & 100 \\
\hline Recursos Hídricos & 1 \\
\hline
\end{tabular}

Quadro 02: Custos de Uso e Cobertura da Terra

\begin{tabular}{|cc|}
\hline DECLIVIDADE & CUSTOS \\
\hline 0 a $5^{\circ}$ & 1 \\
\hline $5^{\circ}$ a $15^{\circ}$ & 100 \\
$15^{\circ}$ a $20^{\circ}$ & 25 \\
$>20^{\circ}$ & 2 \\
\hline Quadro 03: Custos de Declividade
\end{tabular}

\begin{tabular}{|c|c|}
\hline Área de Preservação Permanente & CUSTOS \\
\hline Áreas com Preservação Permanentes & 1 \\
\hline Áreas sem Preservação Permanentes & 50 \\
\hline
\end{tabular}

Quadro 04: Custos de Área de preservação Permanente Fonte: Louzada et al. (2010).

O estabelecimento dos pesos das classes segue as premissas que:

1 - As APP's foram qualificadas segundo seu estágio de preservação e de cobertura por Floresta Estacional Semidecidual, campo rupestre e afloramento rochoso. Também se discriminou as nascentes, cursos d'água, corpos d'água e topos de morros.

2 - Uso e Cobertura da Terra considerou-se que, quanto maior a distância das áreas urbanas (apresentadas por manchas urbanas nas imagens) maior a aptidão para corredor ecológico, bem como se considerou as barreiras existentes criadas pela infraestrutura como rodovias e grande empreendimento. Após o processamento e hierarquização dos dados, utilizou-se a extensão do ArcGIS 10.2, Corridor Designer Toolbox_v0.2, para cálculo da matriz com atribuição dos pesos e notas proporcionais à criação de uma escala de intervalo, sendo utilizado em escala ordinal ou nominal, hierarquizando os eventos segundo a escala de valorização apresentada na figura 03. 


\section{MASULLO, CASTRO, CAPIM}

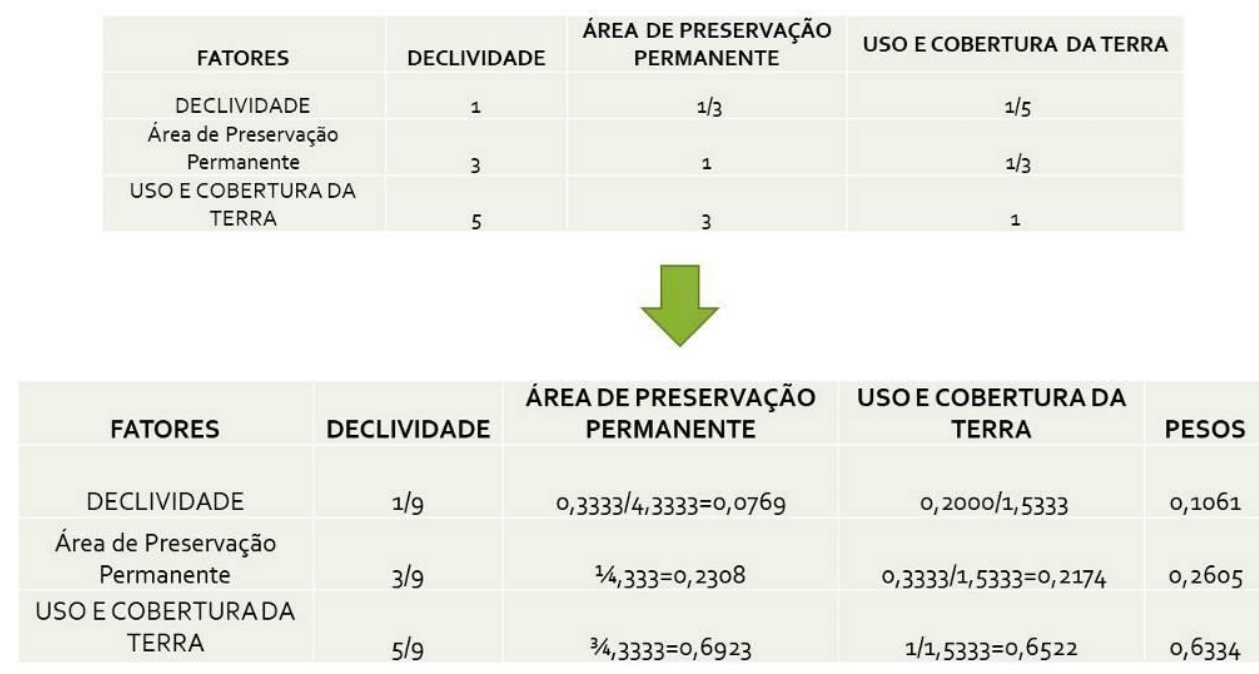

Figura 03: Cálculo da Matriz para os Corredores Ecológicos da Ilha do Maranhão. Fonte: Adaptado LOUZADA et. al, (2010); ROCHA; MASULLO (2016).

O produto dessa hierarquização matricial foi reclassificado e convertido em formato vetorial. Em seguida, houve a sistematização do banco de dados temático utilizados na confecção dos layouts finais dos mapas, que serviram como base para as inferências geográficas realizadas.

\section{RESULTADOS E DISCUSSÃO}

\section{CORREDORES ECOLÓGICOS NA GRANDE SÃO LUÍS: PROPOSIÇÃO E VIABILIDADE}

As regiões metropolitanas possuem habitats fragmentados, o que representa uma das maiores ameaças para a biodiversidade local e regional (TABARELLI; GASCON, 2005). Na Ilha do Maranhão as UC's se apresentam como ambientes cada vez mais tensionados e fragmentados, em decorrência de estruturas (vias, empreendimentos e ocupações) localizadas tanto em suas imediações, quanto em seu interior. Assim, políticas públicas eficazes precisam ser aplicadas de modo a mitigar e, se possível, restaurar as alterações que se manifestam sobre sua dinâmica, diversidade biótica e comunidade local.

\section{CORREDOR APA DO ITAPIRACÓ / APA UPAON-AÇU - MIRITIBA - ALTO DO RIO PREGUIÇAS}

Dentre os corredores ecológicos identificados como viáveis, está o Corredor que interliga as APA's do Itapiracó e a de Upaon-Açu-Miritiba-Alto do Rio Preguiças, passando pelos municípios de Paço do Lumiar, São José de Ribamar e a Capital Maranhense (Figura 04). Ele conecta as áreas conservadas por um percurso de $4,5 \mathrm{~km}$ de extensão, através da 
bacia hidrográfica do Rio Paciência, integrado por seus afluentes, o Rio Itapiracó que se conecta ao rio Boa Vista.

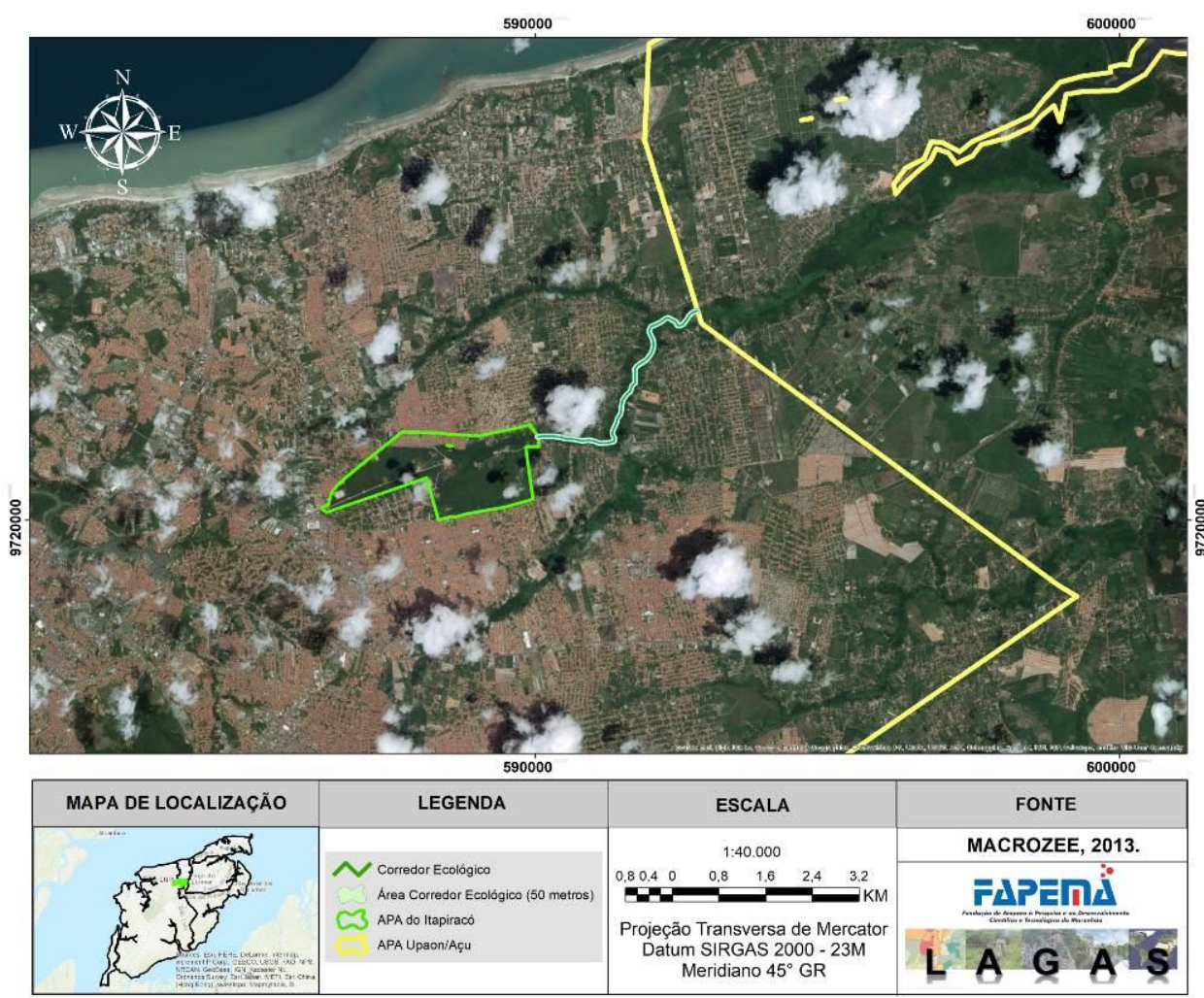

Figura 04: Corredor APA do Itapiracó/APA Upaon-Açu-Miritiba-Alto do Rio Preguiças Fonte: Elaborado pelo autor (2017).

Há grande viabilidade na implementação deste corredor, tendo em vista a dinâmica da paisagem, cuja declividade baixa, entre 0 e $10 \%$ e a existência de mata ciliar protegendo o curso dos rios Boa Vista e Itapiracó, facilitando, a partir de determinadas intervenções urbanísticas, a sua consolidação. A área é adensada, circundada por bairros como Cohab, Cohatrac, Parque Vitória e Turú, bem como diversas habitações do Programa Minha Casa Minha Vida, e grandes condomínios privados. Segundo Masullo (2013), o processo desenvolvido na região resultou tanto na fragmentação quanto na dispersão espacial dos processos produtivos em diferentes escalas, o que ocasionou um avanço de aproximadamente $40 \%$ da ocupação da região nos últimos 20 anos.

A figura 05 apresenta o uso da terra, na qual pode-se observar a prevalência de área urbanizadas e de vegetação secundária. Já as de floresta em estado clímax, se apresentam dispersas quando floresta ombrófila e alinhadas com as drenagens, mais adensadas nas cotas à jusante, nas quais os manguezais representam essa categoria. Apesar desse quadro, há remanescentes significativos de mata para a implantação do Corredor, uma vez que apresenta 
significativa presença de floresta, como se pode ver na figura, este corredor e nas figuras referentes a cada um dos corredores propostos.

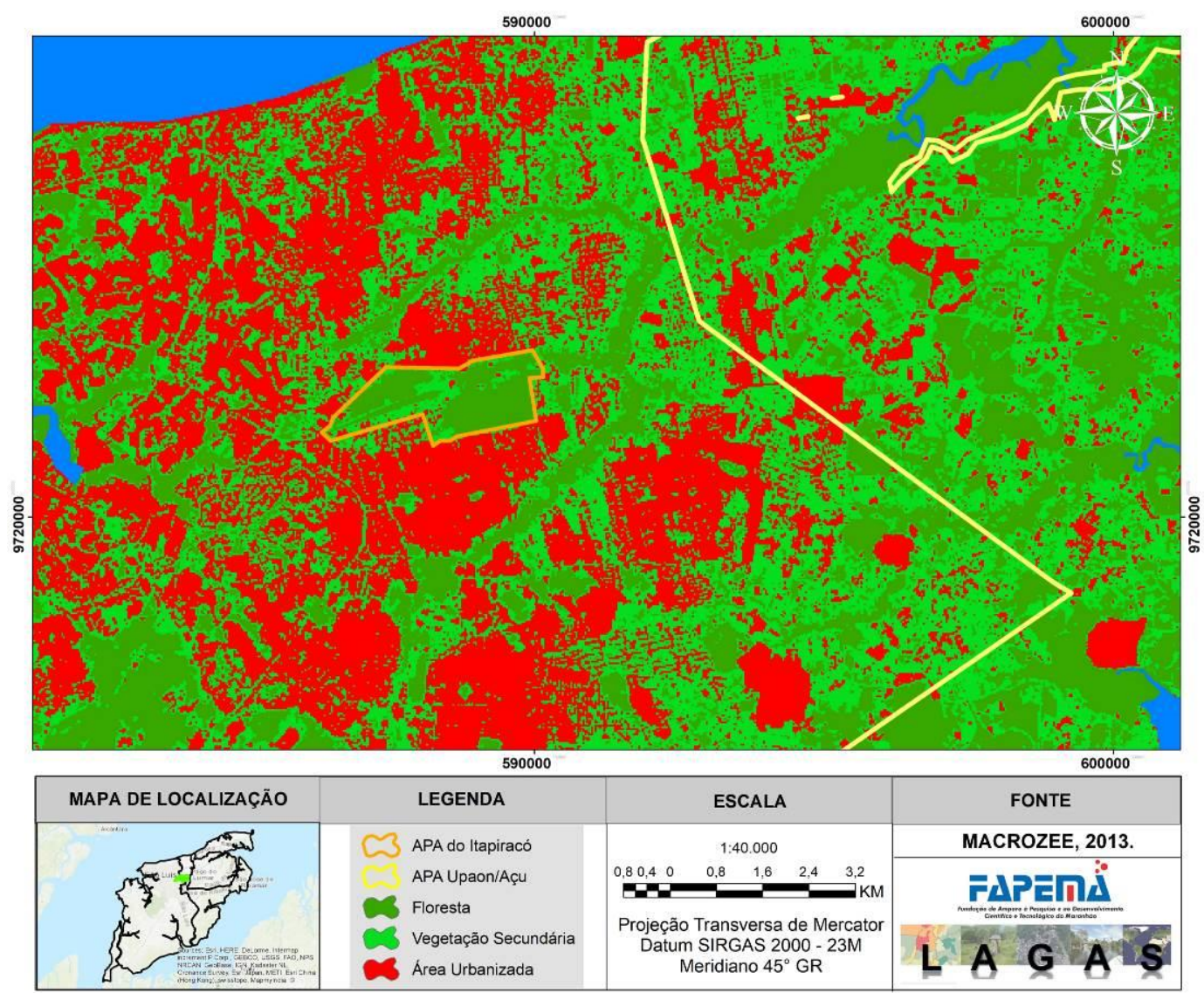

Figura 05: Uso da Terra APA do Itapiracó/APA Upaon-Açu-Miritiba-Alto do Rio Preguiças Fonte: Elaborado pelo autor (2017).

Segundo o IBGE (2010), a área possui percentuais menores que 50\% de coleta de lixo e $25 \%$ de coleta de efluentes, ocasionando no lançamento in natura nos cursos d'água, somando a isto o avanço do desmatamento da mata ciliar e assoreamento do leito dos rios. Essa realidade interfere diretamente na qualidade de vida da população, e na sustentabilidade ambiental das UC's. Segundo os resultados, para a implantação e consolidação desse Corredor algumas intervenções específicas têm caráter imediato, como:

1. Revitalização dos Rios Itapiracó, Boa Vista e Paciência;

2. Manutenção e recuperação de áreas de preservação permanente;

3. Recuperação e recomposição florística de áreas degradadas;

4. Ampliação da coleta e tratamento de efluentes;

5. Realocação dos moradores das áreas de risco a inundações. 
A segunda proposta de Corredor Ecológico na Ilha do Maranhão interligará as UC's do Parque Estadual do Bacanga, APA do Maracanã e APA Upaon-Açu - Miritiba - Alto do Rio Preguiças (Figura 06). Situado a sudeste do município de São Luís, o corredor terá um percurso de 4,8 km de extensão para conectar essas áreas protegidas.

A região está densamente urbanizada, principalmente por moradias de baixa renda às margens do Rio Tibiri, cuja baixa declividade, entre 0 e 10\%, ocasionando significativa degradação da paisagem pelo desmatamento da mata ciliar e lançando efluentes in natura no leito do rio. Na figura 07, podemos perceber o grau do avanço da área urbanizada.

O relevo local fica mais acentuado às margens da BR 135, superando os $20 \%$ de declividade, o que possibilita intervenções a partir de passagens artificiais que viabilizem a conexão entre as UC's. Ações como estas podem ser consolidadas em parceria com o aeroporto, que vem sofrendo, constantemente, com a invasão de animais e avanço de ocupações por habitações irregulares.

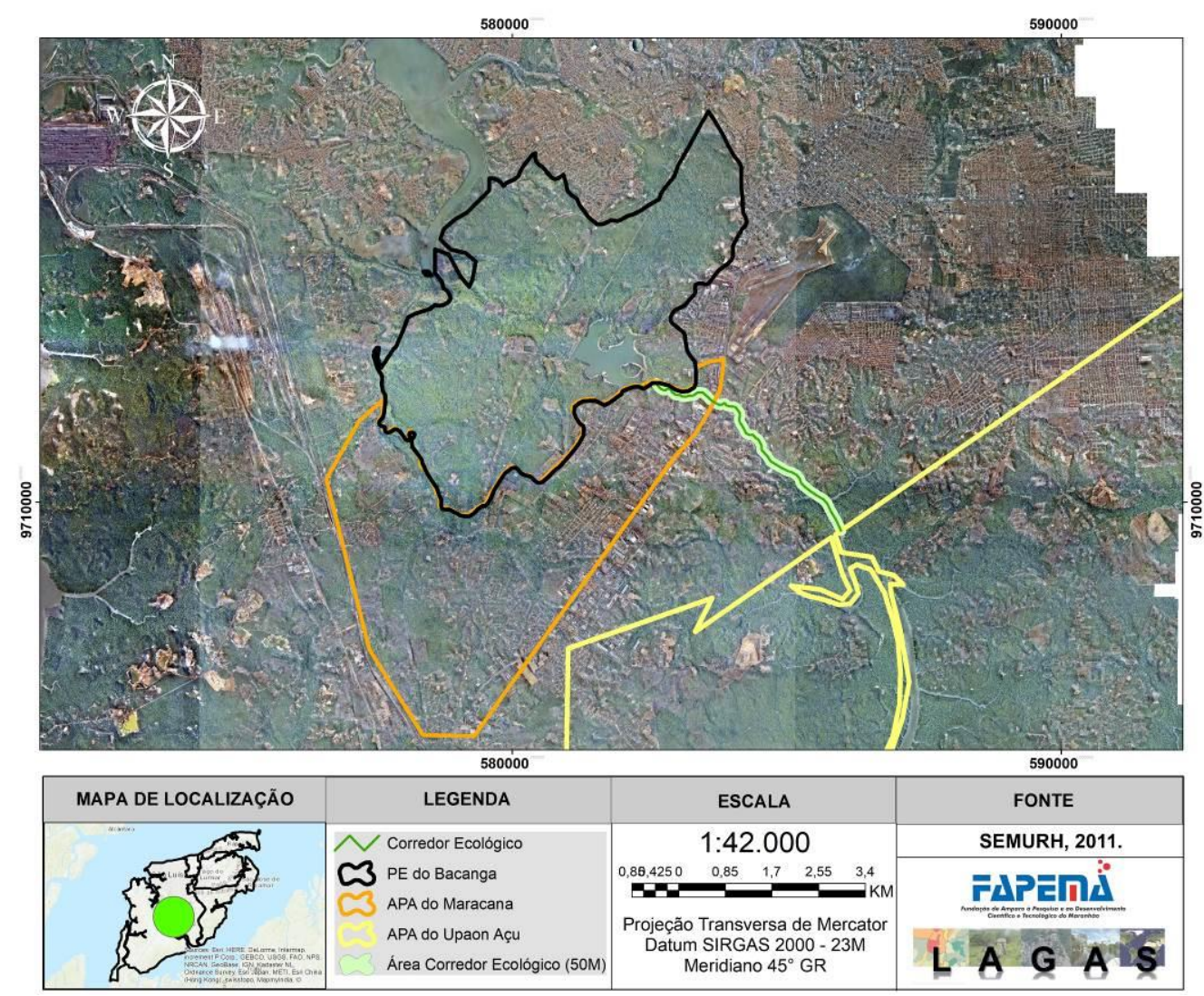

Figura 06: Corredor Parque Estadual do Bacanga / APA do Maracanã / APA Upaon-Açu - Miritiba - Alto do Rio Preguiças

Fonte: Elaborado pelo autor (2017). 


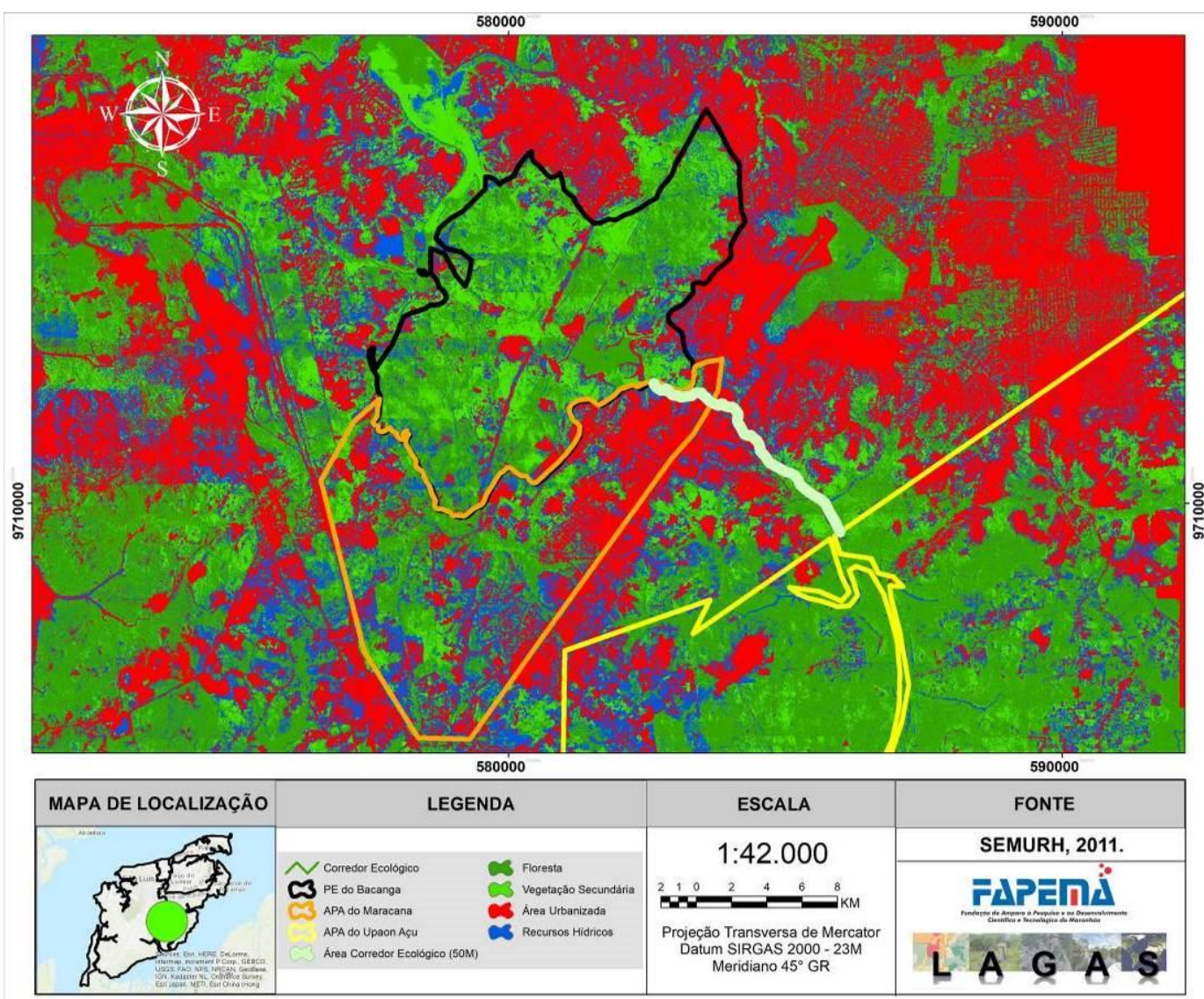

Figura 07: Uso da Terra do entorno do Parque Estadual do Bacanga / APA do Maracanã / APA Upaon-Açu Miritiba - Alto do Rio Preguiças.

Fonte: Elaborado pelo autor (2017).

Assim para este Corredor faz-se necessário as seguintes intervenções urbanísticas específicas para a região:

1. Instalar passagens de fauna artificiais através da BR 135;

2. Consolidação de Parceria entre Governo do Estado e INFRAERO;

3. Revitalização do Rio Tibiri;

4. Manutenção e recuperação de áreas de preservação permanente;

5. Ampliação da coleta e tratamento de efluentes.

\section{CORREDOR PARQUE ESTADUAL DO RANGEDOR; PARQUE DAS DUNAS; SITIO SANTA EULÁLIA / LAGOA DA JANSEN}

A terceira proposta de Corredor Ecológico na Ilha do Maranhão interligará as UC's do Parque Estadual do Rangedor, Sítio Santa Eulália, Parque das Dunas e Lagoa da Jansen. Esta proposta se diferencia das demais, por buscar integrar os conceitos de CE e CVU's, com o objetivo de interligar as áreas protegidas com nível de proteção integral e uso sustentável.

Situado a noroeste do município de São Luís, o corredor divide-se em 03 (três) trajetos que interligam as áreas, $\mathrm{O}$ primeiro (P1) conecta a Parque Estadual do Sítio Rangedor 
ao Parque das Dunas com um percurso de 3.150 metros, o segundo (P2) o Parque Estadual do Rangedor ao Sítio Santa Eulália com uma extensão de 380 metros, enquanto o terceiro trajeto (P3), com extensão de 2 km, conecta a Lagoa da Jansen ao Sítio Santa Eulália (Figura 08).

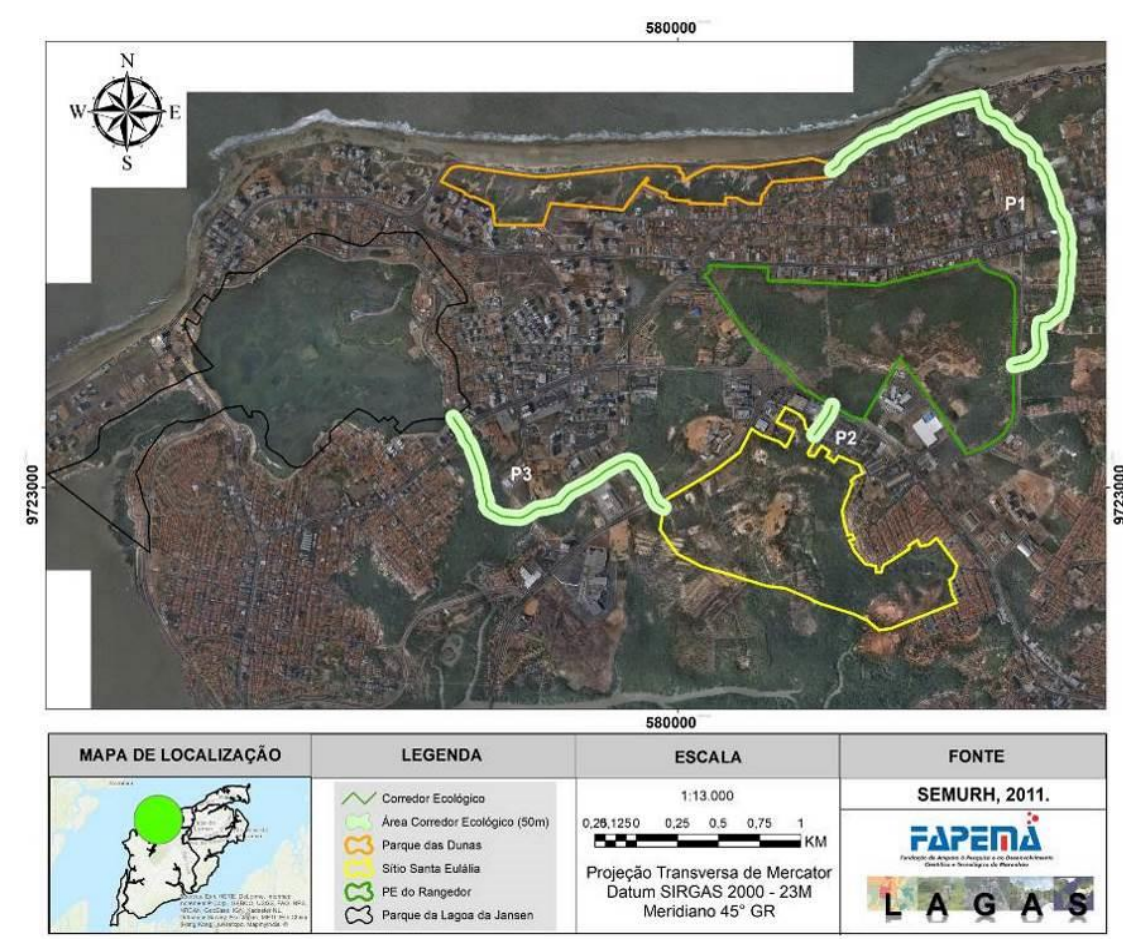

Figura 08: Corredor do Parque Estadual do Sítio Rangedor; Parque das Dunas; Sitio Santa Eulália / Lagoa da Jansen.

Fonte: Elaborado pelo autor (2017).

O primeiro trajeto atravessa a Avenida Eduardo Magalhães e conecta-se com o rio Calhau por 950 metros, até chegar na Avenida dos Holandeses e posteriormente mais 1.050 metros até chegar na foz do referido rio. Após esse percurso, para se interligar ao Parque das Dunas, o trajeto segue margeando por quase de $1 \mathrm{~km}$ na Avenida Litorânea. Já o segundo trajeto atravessa a Avenida Jerônimo de Albuquerque integrando as áreas protegidas por uma faixa de 380 metros, entre o condomínio Novo Tempo e a Concessionária Volkswagen. A região possui uma variação da declividade entre $0 \%$ e $15 \%$, o que possibilita intervenções por meio de passagens artificiais.

O terceiro atravessa a Avenida Euclides Figueiredo no sentido Lagoa da Jansen, passando pela bacia do Rio Anil, atravessando a Avenida Colares Moreira. A declividade da região possibilita uma série de intervenções urbanísticas que viabilizem o corredor, contudo, a grande densidade populacional local e as avenidas que entrecortam e dividem os ambientes, dificultam sua viabilidade. Visando então a efetivação e consolidação da proposta do corredor 
ecológico na região, extremamente adensado (Figura 09) e com habitações de classe média/alta, faz-se necessário uma série de intervenções urbanísticas.

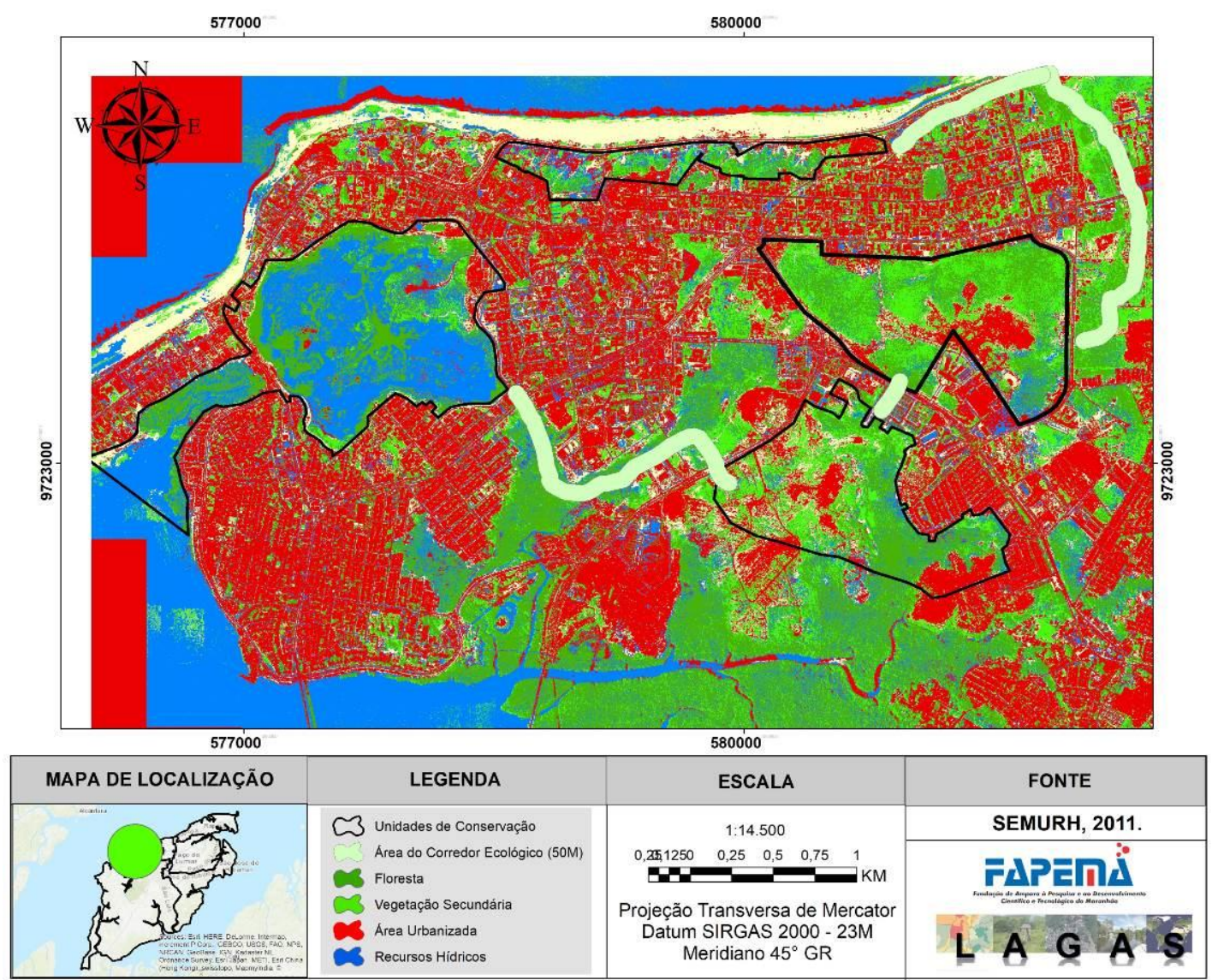

Figura 09: Uso da Terra do entorno da Estação Ecológica do Rangedor; Parque das Dunas; Sitio Santa Eulália / Lagoa da Jansen.

Fonte: Elaborado pelo autor (2017).

Nesse sentido para implantação do corredor ecológico da Estação Ecológica do Rangedor, Parque das Dunas, Sitio Santa Eulália / Lagoa da Jansen, as intervenções e políticas públicas que subsidiem e possibilitem a consolidação e efetivação do mesmo devem atender:

1. Mesclar Corredores Verdes Urbanos e Corredores Ecológicos entre os trajetos 1, 2 e 3 ;

2. Otimizar a arborização de ruas e avenidas atrelado a ciclovias;

3. Instalar passagens de fauna artificiais através das Avenidas Eduardo Magalhães, Jerônimo de Albuquerque e Euclides Figueiredo;

4. Implementar um sistema de poda eficiente, para possibilitar a manutenção da paisagem natural;

5. Incentivar a manutenção de quintais arborizados nos bairros e regiões do entorno, com incentivos fiscais como diminuição do IPTU. 


\section{CONSIDERAÇÕES FINAIS}

As três propostas de Corredores na Ilha do Maranhão são um passo de suma importância para tentar mudar o atual cenário da região. No entanto, a presente pesquisa também reflete a necessidade de se implementar intervenções específicas, de acordo com a dinâmica territorial vigente nas áreas protegidas, juntamente com políticas públicas eficazes que possibilitem ações as quais possam englobar todas as áreas protegidas, e que subsidiem a implementação de projetos ligados à requalificação urbana, culminando no incentivo à preservação do meio ambiente.

Logo, medidas iniciais precisam ser tomadas como consolidação das UC's, objeto de interligação neste estudo para um maior investimento direcionado à gestão e implantação definitivas, maior aporte técnico, resultando no crescimento e eficiência do poder fiscalizatório, bem como na elaboração e atualização de seus Planos de Manejo. Neste cenário, é essencial a elaboração de um Plano de Catalogação de espécies da fauna e da flora, afinal faz-se necessário conhecer a biodiversidade existente nestas unidades, buscando alcançar a precisão das condições necessárias no processo de proposição destes Corredores.

Além destas medidas, observa-se como solução e condição para o avanço nas propostas, em meio ao processo de urbanização consolidado, a integração com os Corredores Verdes Urbanos, ou seja, criação de espaços voltados tanto para o lazer quanto para a proteção dos recursos naturais no âmbito urbano. Essa proposta, contribui também para a requalificação urbana de diversas áreas, proporcionando qualidade de vida à população local.

No entanto, a criação destes CVU's carece de uma gama de medidas, como a arborização de ruas e avenidas atrelada à construção de ciclovias, quadras poliesportivas e outros espaços voltados ao lazer. Somados a estes, apresenta-se como necessário ao desenvolvimento de estímulos efetivos direcionados à manutenção de quintais arborizados nos bairros e regiões do entorno, bem como no desenvolvimento de campanhas socioeducativas, com a finalidade de sensibilizar e engajar a população nesse processo.

Cabe mencionar que os estudos destes três CE's, podem resultar em uma série de benefícios socioambientais na Ilha do Maranhão, como a possível revitalização de importantes recursos hídricos, recomposição da mata ciliar, diminuição do assoreamento, e impactos relacionados às deficiências quanto ao saneamento básico, como é o caso da Lagoa da Jansen, Rio Paciência e o Rio Tibiri. Destaca-se ainda a redução do grau de perturbação sobre espécies que habitam UC's localizadas às margens e/ou próximas do Aeroporto Cunha Machado, e de grandes avenidas da capital, como a Eduardo Magalhães e a dos Holandeses. 
Finalmente, observa-se que as proposições dos CE's demonstram efetivo potencial, por contribuírem com a proteção e manutenção da biodiversidade ainda existentes na Ilha do Maranhão. Considerando elementos que tornam possível sua concretude, o estágio do espaço em sua dialética, neste momento, possibilita a sua viabilidade, bem como contribui com a qualidade de vida de uma área que se encontra em acelerado estágio de adensamento urbano.

\section{REFERÊNCIAS BIBLIOGRÁFICAS}

ANDERSON, A. B; JENKINS, C. N. Applying nature's design: corridors as a strategy for biodiversity conservation. New York: Columbia University Press, 2006.

ARGYRIOU, A.V. et al. GIS multicriteria decision analysis for evaluation and mapping of landscape deformation neotectonics: A case study from Crete. In: Geomorphology, 262 -274. 2016.

ARANHA, A. R. A; ALMIRANTE, M. F. A importância do corredor ecológico: um estudo sobre Parque Estadual "Morro do Diabo" em Teodoro Sampaio-SP. Geografia v. 16, n. 1. Universidade Estadual de Londrina, Departamento de Geociências. Londrina. 2007.

ARAUJO, Ricardo Murilo Padilha de. et. al. Planejando corredores ecológicos para restauração florestal em paisagens fragmentadas: Complexo Industrial de SUAPE.In: V Congresso Brasileiro de Gestão Ambiental. Belo Horizonte - MG.2014.

ARRUDA, M.B. Corredores ecológicos no Brasil- gestão integrada de ecossistemas. IBAMA. Corredores ecológicos- uma abordagem integradora de ecossistemas no Brasil. Brasília. 2003.

AYRES, J.M. et al. Os corredores ecológicos das florestas tropicais do Brasil. Belém, PA: Sociedade Civil Mamirauá, 2005. 256p.BRASIL. Decreto Federal No 4340, de 22 de agosto de 2002.

BENNETT, A. F. Linkages in the landscape: the role of corridors and connectivity in wildlife conservation. $2^{\mathrm{a}}$ ed. IUCN, Gland, Switzerland and Cambridge, UK, 2003.

BONTEMPO, K. P. A contribuição do uso público para a conservação das áreas urbanas de interesse ambiental: a micro-bacia do Jaracaty em São Luís. Dissertação (mestrado). Universidade Federal da Bahia. Escola Politécnica. Salvador. 2008.

BRASIL. Lei $\mathrm{n}^{\circ}$ 9.985, de 18 de julho de 2000. Regulamenta o art. 225, § 1o, incisos I, II, III e VII da Constituição Federal, institui o Sistema Nacional de Unidades de Conservação da Natureza e dá outras providências. Diário Oficial [da] União, Brasília, DF, 19 de julho de 2000.

BRITO, Francisco. Corredores ecológicos: uma estratégia integradora na gestão de ecossistemas. Florianópolis: Editora da UFSC, 2006.

BURSZTYN; Maria Augusta; BURSZTYN, Marcel. Fundamentos de políticas e gestão ambiental: os caminhos do desenvolvimento sustentável. Rio de Janeiro: GARAMOND. 2012.

BUENO, N. P. E; RIBEIRO, K. C. C. Unidades de Conservação-caracterização e relevância social, econômica e ambiental: um estudo acerca do Parque Estadual Sumaúma. Revista Eletrônica Aboré-Publicação da Escola Superior de Artes e Turismo Manaus. 2007.

BENSUSAN, Nurit. Conservação da biodiversidade em áreas protegidas. Rio de Janeiro: Editora FGV, 2006. 
BRAGA, V.D. O papel dos espaços protegidos privados para a conservação da biodiversidade. Dissertação, Centro de Desenvolvimento Sustentável.Universidade de Brasília. 2010.

CEZAR, Adelaine; ZEILHOFER, Peter. Geoprocessamento no planejamento de corredores ecológicos: proposta para ligação das terras indígenas Japuíra e Serra Morena, MT. III Simpósio Brasileiro de Ciências Geodésicas e Tecnologias da Geoinformação002 - 006. Recife - PE. 2010.

COSTA, N. F. A. da et al. Efeitos da urbanização na área de Proteção Ambiental do Itapiracó, São Luís, MA. Boletim do Laboratório de Hidrobiologia, 2008.

COUTINHO, Luciano Melo. Zoneamento de áreas potenciais para reflorestamento via lógica Fuzzy e AHP. IN: XVII SBSR. INPE. João Pessoa. 2015.

DIAS, Valdirene Silva Brito. AHP na modelagem da vulnerabilidade ambiental do mini corredor ecológico serra das onças (BA). In: Revista Brasileira de Cartografia 1363-1377. 2014.

FERRARI, J.L. et al. Corredores ecológicos potenciais na sub-bacia hidrográfica do córrego Horizonte, Alegre-ES, indicados por meio de SIG. Rev. Bras. Ciênc. Agrár. Recife, v.7, n.1, p.133-141, 2012.

FONSECA, G. A. B. et al. Desafiando o fim da natureza. In: Zarin, Daniel J. As Florestas produtivas nos neotrópicos- Conservação por meio de manejo sustentável. IEB- Instituto Internacional de Educação do Brasil, p. 367-389.Brasília. 2005.

FORMAN, R.T.T. Land Mosaics. Great Britain: Cambridge University Press, 1995.

GAUER. Natália Peppes. Avaliação da vulnerabilidade ambiental por meio de um modelo de análise multicritério no norte da planície costeira do Rio Grande do Sul, Brasil. Monografia em Ciências Biológicas. Universidade Federal do Rio Grande do Sul. IMBÈ, 2015.

JUNIOR, C.H.L.S. et al. Análise multitemporal do uso e cobertura do solo da Área de Proteção Ambiental do Itapiracó no período de 1999 a 2010 em São Luís-MA. Universidade CEUMA- Projeto Interdisciplinar, 2011.

LEVERINGTON, F. et. al. Management effectiveness evaluation in protected areas - a global study. The University of Queensland Brisbane. Second edition. Australia. p. 101. 2010.

LOUZADA, F. L. R de O. et al. Delimitação de corredores ecológicos no ArcGIS 9.3. Mundo da Geomática. Universidade Federal do Espirito Santo, 2010.

MMA (Ministério do Meio Ambiente); Dados Consolidados do Cadastro Nacional de Unidades de Conservação (CNUC). Brasília: Ministério do Meio Ambiente. 2017. Disponível em: <http://www.mma.gov.br/images/arquivo/80112/CNUC_FEV17\%20\%20C_Bio.pdf>

MANĀUS. Proposta de criação do corredor ecológico urbano sauim-de-coleira. 2015.

MARQUES, Luciene et al. Metodologia para a definição de áreas favoráveis para implantação de corredor ecológico, utilizando ferramenta do Sistema de Informação Geográfica. Anais XV Simpósio Brasileiro de Sensoriamento Remoto - SBSR, INPE p.4436. Curitiba, PR. 2011.

MASULLO, Yata Anderson Gonzaga. Avaliação da dinâmica espacial da dengue em relação às questões socioambientais no distrito sanitário da COHAB no município de São Luís - MA. Dissertação (Mestrado) - Universidade Estadual do Maranhão, Programa de Pós-Graduação em Desenvolvimento Socioespacial e Regional, 2013.

MASULLO, Yata Anderson Gonzaga; MAGALHÃES; Silvia Glacyane de Almeida. Análise Socioeconômica e Ambiental das Unidades de Conservação do Estado do Maranhão. Relatório de Pesquisa. Fundação de Amparo à Pesquisa e ao Desenvolvimento Científico e Tecnológico do Maranhão - FAPEMA. São Luís. 2015. 
MASULLO, Yata Anderson Gonzaga. LOPES; José Antonio Viana Os desafios da gestão interfederativa frente aos indicadores sociais da região metropolitana da grande São Luís - MA. Rev. Tamoios, São Gonçalo (RJ), ano 12, n. 1, págs. 62-83, jan/jun. 2016.

MEDEIROS, R. Evolução das tipologias e categorias de áreas protegidas no Brasil. Ambiente \& Sociedade - Vol. IX $\mathrm{n}^{\mathrm{o}}$. 1 jan./jun. 2006.

MMA. Resolução CONAMA 09/1996. Brasília: MMA/CONAMA, 1996.Disponível em: http://www.mma.gov.br/port/conama/legiabre.cfm?codlegi=208. Acesso em: fev.2016.

Série corredores ecológicos- 12 anos de trabalho pela conservação da biodiversidade nacional. Brasília, 2015.

MINAYO, M. C.de S. et al. Pesquisa Social: Teoria, método e criatividade.16ed. Ed. Vozes. Petrópolis. 2000.

MORIN, E. et al. Educar na era planetária: o pensamento complexo como método de aprendizagem pelo erro e incerteza humana. Trad. Sandra Trabucco Valenzuela. São Paulo: Cortez; Brasília; UNESCO, 2003.

MUCHAILH, M.C. Análise da paisagem visando à formação de corredores de biodiversidade: Estudo de caso da porção superior da bacia do rio São Francisco Falso, Paraná. Dissertação de Mestrado. Universidade Federal do Paraná. Curitiba. 2007.

NASCIMENTO, Iara S. do; CRUZ, Carla B. M; NEVES, Sandra M. A. da S; GALVANIN; Edineia A. dos S. Avaliação da exatidão dos classificadores Maxver e Iso Cluster do software ArcGIS for desktop, com uso de imagem Landsat 8 do município de Cáceres/MT. Revista Continentes (UFRRJ), ano 5, n. 8, p. 48-62. 2016.

NUNES, G.M., Souza Filho, C.R.S., Vicente, L.E., Madruga, P.R.A; Watzlawick, L.F. Sistemas de Informações Geográficas aplicados na implantação de corredores ecológicos na Sub-Bacia Hidrográfica do Rio Vacacaí-Mirim (RS): In Anais do $12^{\circ}$ Simpósio Brasileiro de Sensoriamento Remoto, Goiânia. 2005.

OLIVEIRA, V. S. de et al. Uso e ocupação humana em área de corredor ecológico no bioma caatinga: políticas públicas como meio de satisfação do desenvolvimento sustentável. VII Encontro da Sociedade Brasileira de Economia Ecológica. Fortaleza, 28 a 30 de novembro de 2007.

OLIVEIRA, Evagelina. Redes e Regionalização da Saúde. In: BARCELLOS, Christovam. A geografia e o contexto dos problemas de saúde. Rio de Janeiro. ABRASCO. p. 223 - 230, 2008.

PEDLOWSKI, M. et al. A criação de áreas protegidas e os limites da conservação ambiental em Rondônia. Ambiente \& Sociedade - Ano II - $\mathrm{N}^{\circ} 5-2^{\circ}$ Semestre de 1999.

PEREIRA, V.H.C; CESTARO, L.A. Corredores ecológicos no Brasil: avaliação sobre os principais critérios utilizados para definição de áreas potenciais. Caminhos de Geografia Uberlândia v. 17, n. 58 p. 16-33. 2016.

PENTEADO, H.M; ALVAREZ, C.E. de. Corredores verdes urbanos: estudo da viabilidade de conexão das áreas verdes de Vitória. Paisagem Ambiente: ensaios - n. 24 São Paulo - p. 57 - 68 - 2007.

PRIMACK, R.B.; RODRIGUES, E. Biologia da conservação. Londrina. 2001.

RAFFO; Jorge Gustavo da Graça. O processo analítico hierárquico e seu uso na modelagem do espaço geográfico. In: Revista do Departamento de Geografia - USP, Volume Especial 30 Anos. p. 26-37. São Paulo. 2012.

ROCHA, Roberta Capim; MASUllO, Y. A. G. Corredores Ecológicos na Ilha do Maranhão. Relatório de Pesquisa. Fundação de Amparo à Pesquisa e ao Desenvolvimento Científico e Tecnológico do Maranhão - FAPEMA. São Luís. 2016.

SHAO, Huaiyong. A method to the impact assessment of the returning grazing land to grassland project on regional eco-environmental vulnerability. In: Environmental Impact Assessment Review, 155-167. 2016. 
SAHOO. S. etal. Environmental vulnerability assessment using Grey Analytic Hierarchy Process based model. In: Environmental Impact Assessment Review. 145-154. 2016. SAITO, Nathalia Suemi et. al. Geotecnologia e Ecologia da Paisagem no Monitoramento da Fragmentação Florestal. In: Revista Floresta e Ambiente. 2015.

SEOANE, C. E. S. et al. Corredores ecológicos como ferramenta para a desfragmentação de florestas tropicais. Pesquisa Florestal Brasileira, Colombo, v.30, n.63, p. 207-216. 2010. SILVA JUNIOR, Celso Henrique Leite. Lógica Fuzzy e Processo Analítico Hierárquico AHP na avaliação da qualidade ambiental de nascentes. In: Revista Eletrônica em Gestão, Educação e Tecnologia Ambiental Santa Maria, v. 19, n. 2, mai-ago., p. 292-303. Santa Maria - RS. 2015.

TABARELLI, M; GASCON, C. Lessons from fragmentation research: improving management and policy guidelines for biodiversity conservation. Conservation Biology, vol. 19, no. 3, p. 734-739. 2005.

UMEDA, C.Y.L. et al. Uso de sensoriamento remoto na identificação de corredores ecológicos: estudo de caso da bacia hidrográfica do Rio Formoso, Bonito, MS. Eng Sanit Ambient | v.20 n.4| 551-557. 2015

VALENTI, M. W. et al. Educação ambiental em unidades de conservação: políticas públicas e a prática educativa. Educação em Revista. Belo Horizonte. v.28. n.01. p.267288. 2012. 